\title{
Brake spesific fuel consumption, brake thermal efficiensy, dan emisi gas buang mesin bensin EFI dengan sistem EGR berbahan bakar premium dan butanol
}

\author{
Firman Lukman Sanjaya ${ }^{1 *}$, Syaiful ${ }^{2}$, Syarifudin $^{3}$ \\ ${ }^{1,3}$ Program Studi Teknik Mesin, Politeknik Harapan Bersama \\ Jl. Mataram no.9, Kota Tegal, Jawa Tengah, Indonesia \\ 2Jurusan Teknik Mesin, Fakultas Teknik, Universitas Diponegoro \\ JI. Prof. Soedarto SH, Tembalang, Semarang, Indonesia \\ ${ }^{*}$ Corresponding author: sanjaya.firman51@gmail.com
}

\begin{abstract}
The increase in vehicle volume causes an increase in the use of gasoline fuel and air pollution. Therefore, alternative fuels such as butanol are one of the solutions to overcome this problem. Butanol has a high octane value and oxygen content so that the combustion process is more perfect and reduces exhaust emissions. The use of butanol is expected to improve engine performance and reduce exhaust emissions. The purpose of this study was to observe the effect of butanol on gasoline engines with the EGR system on Brake Specific Fuel Consumption (BSFC), Brake Thermal Efficiency (BTE), and exhaust emissions. Testing uses a Toyota Kijang $7 \mathrm{~K}$ gasoline engine with an EFI fuel system. The percentage of butanol used is $5 \%, 10 \%, 15 \%$ in the condition without EGR, hot EGR, and cold EGR. The test is carried out at a fixed engine rotation speed of $2500 \mathrm{rpm}$. Retrieval of engine performance data using a dynamometer while the exhaust emissions using the GA analyzer. The test results showed the addition of butanol increased the BSFC value by $0.9 \%$ and BTE by $2 \%$. However, a decrease occurred in $\mathrm{CO}$ emissions by $74.2 \%$ and $\mathrm{HC}$ by $33.6 \%$ compared to pure premium. The use of hot EGR decreased BSFC by $19.3 \%$ and BTE by $23.9 \%$. The highest CO emissions were $3.23 \%$ while the highest HC emissions of 259 ppm occurred in the use of cold EGR.
\end{abstract}

Keywords : butanol, EGR, BSFC, BTE, exhaust gas emissions

\begin{abstract}
Abstrak
Peningkatan volume kendaraan menyebabkan peningkatan penggunaan bahan bakar bensin dan polusi udara. Oleh karena itu, bahan bakar alternatif seperti butanol adalah salah satu solusi untuk mengatasi masalah tersebut. Butanol memiliki nilai oktan dan kandungan oksigen yang tinggi sehingga proses pembakaran lebih sempurna dan mereduksi emisi gas buang. Penggunaan butanol diharapkan dapat meningkatkan performa mesin dan menurunkan emisi gas buang. Tujuan penelitian ini adalah untuk mengobservasi pengaruh butanol pada mesin bensin dengan sistem EGR terhadap Brake Spesific Fuel Consumption (BSFC), Brake Thermal Efficiency (BTE) dan emisi gas buang. Pengujian menggunakan mesin bensin toyota kijang $7 \mathrm{~K}$ dengan sistem bahan bakar EFI. Prosentase butanol yang digunakan 5\%, 10\%, 15\% pada kondisi tanpa EGR, EGR panas dan EGR dingin. Pengujian dilakukan pada kecepatan putaran mesin tetap $2500 \mathrm{rpm}$. Pengambilan data performa mesin menggunakan dynamometer sedangkan emisi gas buang menggunakan gaz analyzer. Hasil pengujian menunjukkan penambahan butanol meningkatkan nilai BSFC sebesar 0,9\% dan BTE sebesar 2\%. Namun, penurunan terjadi pada emisi $\mathrm{CO}$ sebesar 74,2\% dan $\mathrm{HC}$ sebesar 33,6\% dibanding premium murni. Penggunaan EGR panas menurunkan BSFC sebesar 19,3\% dan BTE sebesar 23,9\%. Emisi CO tertinggi sebesar 3,23\% sedangkan emisi HC tertinggi sebesar 259 ppm terjadi pada penggunaan EGR dingin.
\end{abstract}

Kata kunci: Butanol, EGR, BSFC, BTE, emisi gas buang 


\section{Pendahuluan}

Peningkatan volume kendaraan mengakibatkan penggunaan bahan bakar bensin meningkat. Hal ini menyebabkan kelangkaan bahan bakar fosil. Selain itu, emisi gas buang yang dihasilkan kendaraan menyebabkan tingginya polusi udara. Oleh karena itu, perlu adanya bahan bakar alternative yang mampu menggantikan bahan bakar bensin yang dapat diperbaharui dan ramah lingkungan [1].

Butanol merupakan bahan bakar alternatif yang memiliki karakteristik lebih baik dan dapat menggantikan bahan bakar bensin. Butanol memiliki nilai oktan yang tinggi sehingga mampu menahan tekanan tinggi saat langkah kompresi. Hal ini mengakibatkan performa mesin meningkat [2]. Panas laten penguapan yang tinggi pada butanol menyebabkan bahan bakar menguap lebih baik sehingga proses pembakaran lebih baik dan mengingkatkan efisiensi termal mesin [3].

Butanol juga dapat mereduksi emisi $\mathrm{CO}$ dan $\mathrm{HC}$ karena tingginya kandungan oksigen pada butanol yang menyebabkan proses pembakaran dalam ruang bakar lebih sempurna. Namun, butanol meningkatkan emisi Nitrogen Oxide $\left(\mathrm{NO}_{\mathrm{x}}\right)$ [4][5]. Campuran nitrogen dan oksigen yang terpapar oleh suhu tinggi menghasilkan emisi $\mathrm{NO}_{\mathrm{x}}$. EGR (Exhaust Gas Recirculation) merupakan sistem pada mesin yang dapat mereduksi emisi $\mathrm{NO}_{\mathrm{x}}$. Cara kerja EGR yaitu mensirkulasi kembali sebagian dari gas buang dari exhaust manifold kembali ke ruang bakar (combustion chamber) [6]. Selain itu, EGR juga mampu meningkatkan penghematan konsumsi bahan bakar. Hal ini karena bahan bakar yang tidak terbakar disirkulasikan kembali ke ruang bakar sehingga injektor mengurangi jumlah bahan bakar yang disemprotkan [7]. Penggunaan EGR juga menyebabkan peningkatan kualitas pembakaran dan thermal efficiency [8].

Menurut Yuanxu Li (2018) [4] butanol memiliki nilai kalor rendah sehingga temperatur pada ruang bakar menurun. Hal ini mengakibatkan kebutuhan bahan bakar meningkat. Yunqian Li (2016)
[3] menjelaskan pada penelitiannya bahwa panas laten penguapan yang tinggi pada butanol menyebabkan proses penguapan bahan bakar lebih baik sehingga pembakaran dalam silinder meningkat. Hal ini dapat meningkatkan efisiensi termal mesin. Sependapat dengan penelitian sebelumnya, Syarifudin (2019) [9] memaparkan bahwa butanol mampu meningkatkan efisiensi termal mesin karena tingginya kadar oksigen pada butanol yang dapat meningkatkan proses pembakaran. Menurut Zheng, dkk. (2017) [10] juga menjelaskan tingginya kandungan oksigen pada butanol mampu mereduksi emisi $\mathrm{CO}$ dan HC. Namun, penggunaan butanol meningkatkan emisi $\mathrm{NO}_{\mathrm{x}}$.

$$
\text { Deepak Agarwal (2011) [11] }
$$

menjelasakan bahwa sistem EGR mensirkulasikan kembali sebagian gas buang ke ruang bakar. Oksigen dari udara segar yang masuk tergantikan oleh gas buang hasil sirkulasi sehingga konsentrasi oksigen pada ruang bakar menurun dan meningkatkan panas spesifik campuran udara. Hal ini menghasilkan suhu api yang lebih rendah sehingga sistem EGR dapat mereduksi $\mathrm{NO}_{\mathrm{x}}$. Fangxi Xie (2017) [7] pada penelitiannya menjelaskan bahwa sistem EGR membawa beberapa bahan bakar yang tidak terbakar kembali keruang bakar dan membantu proses pembakaran. Hal ini menyebabkan bahan bakar yang diinjeksikan ke ruang bakar menurun. Dari hasil penelitian Haiqiao Wei, dkk., (2012) [8] dapat dijelaskan bahwa penggunaan EGR meningkatkan Break Thermal Efficiency karena adanya gas buang yang menggantikan udara segar yang masuk ke dalam silinder sehingga prosentase oksigen mengalami peningkatan.

Penambahan butanol pada bahan bakar bensin dapat meberikan dampak positif pada mesin. Sistem EGR juga dapat memperbaiki performa mesin. Oleh karena itu, penelitian ini mengobservasi brake spesific fuel consumption, brake thermal efficiency, dan emisi gas buang mesin bensin EFI berbahan bakar premium dan butanol dengan sistem EGR.

\section{Tinjuaun Teoritis}


1. Brake Spesific Fuel Consumption

Brake spesific fuel consumption adalah mengindikasikan banyaknya bahan bakar yang diperlukan untuk menghasilkan satu satuan daya [12].

$$
B S F C=\frac{m f}{P}
$$

$B S F C$ adalah konsumsi bahan bakar spesifik (kg/kW.jam), $m f$ adalah laju aliran massa bahan bakar (kg/jam), dan $\mathrm{P}$ adalah daya $\operatorname{mesin}(\mathrm{kW})$.

\section{Brake Thermal Efficiency}

Brake Thermal Efficiency (BTE) adalah mengindikasikan seberapa besar energi dari bahan bakar dikonversi menjadi tenaga. Besarnya brake thermal efficiency (BTE) dapat diformaliskan sebagai berikut [12]:

$$
B T E=\frac{P}{\dot{m}_{f} Q_{H V}}
$$

Dimana BTE adalah efisiensi termal (\%), $\mathrm{Q}_{\mathrm{HV}}$ merupakan nilai kalor dari bahan bakar $(\mathrm{MJ} / \mathrm{kg})$ dan $m_{f}$ adalah laju aliran massa bahan bakar (kg/jam).

\section{Metode Penelitian}

Penlitian ini bertujuan untuk mengetahui nilai Brake Spesific Fuel Consumption (BSFC), Brake Thermal Efficiency (BTE) dan emisi gas buang mesin bensin pada kondisi tanpa EGR, EGR panas dan EGR dingin. Bahan bakar yang digunakan adalah premium $(\mathrm{P})$ dan butanol (B) dengan prosentase campuran butanol 5\% (PB5), 10\% (PB10) dan 15\% (PB15) dari total volume campuran bahan bakar. Sifat-sifat fisik bahan bakar ditampilkan pada Tabel 1. Penelitian ini menggunakan mesin bensin EFI dengan spesifikasi mesin seperti pada Tabel 2. Percobaan dilakukan dengan kecepatan putaran mesin tetap 2500 rpm. Mesin bensin dan perlengkapannya disusun sesuai dengan Gambar 1. Aliran bahan bakar diukur untuk menentukan konsumsi bahan bakar mesin. Output mesin terhubung ke dinamometer tipe DYNOmite Land \& Sea untuk mengukur performa pada mesin. Emisi gas buang diukur menggunakan alat analisa gas ( $\mathrm{Gaz}$ Analyzer) Stargass 898. Pengukuran emisi gas buang digunakan untuk menentukan tingkat $\mathrm{HC}$ dan $\mathrm{CO}$.

Tabel 1. Propertis bahan bakar

\begin{tabular}{clccc}
\hline $\mathrm{N}$ & Propertis & $\begin{array}{c}\text { Satua } \\
\mathrm{n}\end{array}$ & $\begin{array}{c}\text { Premi } \\
\mathrm{um}\end{array}$ & $\begin{array}{c}\text { But } \\
\text { anol }\end{array}$ \\
\hline 1 & $\begin{array}{l}\text { Angka } \\
\text { Oktan }\end{array}$ & $\mathrm{RON}$ & 88 & 98,3 \\
\hline 2 & Kadar Air & $\% \mathrm{~V}$ & 0,003 & $>5$ \\
\hline $\begin{array}{l}\text { Viskositas } \\
\text { (pada suhu } \\
\left.40^{\circ} \mathrm{C}\right)\end{array}$ & $\mathrm{mm}^{2} / \mathrm{s}$ & 0,22 & 2,63 \\
\hline 4 & Nilai Kalor & $\mathrm{MJ} / \mathrm{kg}$ & 42,7 & 33,3 \\
\hline 5 & $\begin{array}{l}\text { Kandungan } \\
\text { Oksigen }\end{array}$ & $\%$ & - & 21,6 \\
\hline 6 & Massa Jenis & $\mathrm{Kg} / \mathrm{m}^{3}$ & 744 & 815 \\
\hline
\end{tabular}

Tabel 2. Sepesifikasi mesin bensin

\begin{tabular}{ll}
\hline Merk & Kijang 7K \\
\hline Produksi & Toyota \\
\hline Tipe Mesin & Bensin \\
\hline Jumlah Silinder & 4 \\
\hline Kapasitas & $1789 \mathrm{cc}$ \\
\hline Jumlah Katup & (SOHC) 8 Katup \\
\hline Daya Maksimum & $94 \mathrm{Hp}-5000 \mathrm{rpm}$ \\
\hline Torsi Maksimum & $\begin{array}{l}155 \mathrm{~N} . \mathrm{m}-3200 \\
\mathrm{rpm}\end{array}$ \\
\hline $\begin{array}{l}\text { Sistem Bahan } \\
\text { Bakar }\end{array}$ & EFI \\
\hline
\end{tabular}

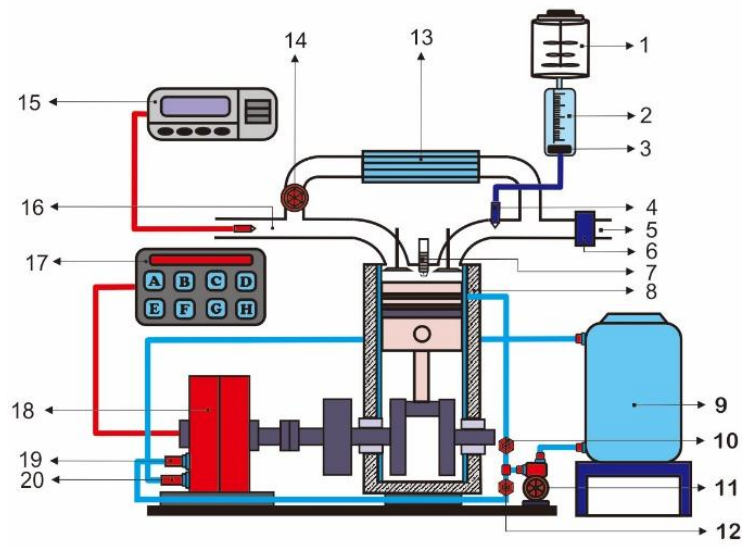

Gambar 1. Eksperimental Set Up Keterangan Gambar 1: 
1. Mixer

2. Burret

3. Pompa bahan bakar

4. Injektor

5. Intake manifold

6. Air flow sensor

7. Busi

8. Mesin bensin

9. Tangki air

10. Katup air pendingin

11. Pompa air

12. Katup air pembebanan

13. EGR cooler

14. Katup EGR

15. Gaz analyzer

16. Exhaust manifold

17. Panel display utama

18. Dynamometer

19. Saluran air masuk

20. Saluran air keluar

Bahan bakar bensin dan butanol dicampurkan menggunakan mixer sehingga bahan bakar tercampur secara homogen. Bahan bakar yang sudah tercampur dialirkan ke injektor dengan bantuan pompa bahan bakar melalui buret. Buret berfungsi sebagai alat ukur bahan bakar yang terpakai selama proses pengujian dalam satuan waktu. Setelah itu bahan bakar disemprotkan ke ruang bakar oleh injektor bahan bakar. Kecepatan mesin terbaca pada monitor oleh tachometer dengan mendeteksi putaran mesin menggunakan sensor jarak. Dynamometer digunakan untuk mengukur torsi yang dihasilkan mesin. Poros Dynamometer terpasang secara inline dengan poros out mesin sehingga tenaga yang dihasilkan mesin langsung tersalurkan pada dynamometer. Beban mesin tetap 25\% dari kemampuan beban yang dapat dicapai oleh mesin dengan mengubah laju aliran air yang mengalir ke dynamometer. Besarnya torsi yang dibaca oleh dynamometer ditampilkan pada display beban.

Percobaan dilakukan dengan variasi prosentase campuran bahan bakar dengan kecepatan putaran mesin tetap yaitu 2500 rpm. Beberapa gas buang disirkulasikan (EGR) kembali ke intake manifold dan tercampur oleh udara segar yang masuk dalam silinder. Gas analyser digunakan untuk mengukur emisi gas buang hasil dari pembakaran mesin.

\section{Hasil dan Pembahasan}

\section{Brake Spesific Fuel Consumption (BSFC)}

Penelitian ini menggunakan variasi campuran bahan bakar premium-butanol dengan prosentase butanol 5\%, 10\%, dan $15 \%$. Nilai BSFC dengan dan tanpa menggunakan sistem EGR dibandingkan dengan hasil nilai BSFC pada tiap variasi campuran bahan bakar. Hasil pengujian BSFC untuk variasi campuran bahan bakar dengan dan tanpa EGR ditunjukkan pada Gambar 2.

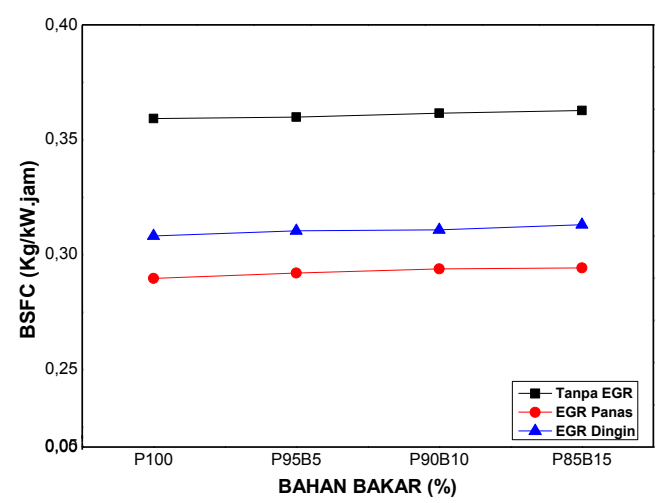

Gambar 2. Brake spesific fuel consumption mesin bensin untuk variasi campuran bahan bakar dengan dan tanpa EGR pada putaran mesin $2500 \mathrm{rpm}$

Hasil pengujian menunjukkan bahwa penambahan butanol pada bahan bakar premium meningkatkan BSFC mesin bensin. Peningkatan nilai BSFC tertinggi sebesar $0,9 \%$ pada campuran bahan bakar BP15 dibanding premium murni (P100). Peningkatan BSFC karena rendahnya nilai kalor (LHV) butanol dibanding premium sehingga terjadinya penurunan temperatur ruang bakar yang menyebabkan jumlah injeksi bahan bakar lebih banyak untuk mempertahankan panas ruang di keadaan idealnya. Oleh karena itu, konsumsi bahan bakar meningkat [13]. Penggunaan EGR menurunkan nilai BSFC mesin bensin. Hal ini karena bahan bakar yang tidak terbakar tersirkulasikan kembali ke ruang bakar dan 
membantu proses pembakaran selanjutnya sehingga bahan bakar yang perlu diijeksikan berkurang [7][14]. Penggunaan EGR panas dapat menurunkan BSFC tertinggi hingga 19,33\% dibanding tanpa EGR.

\section{Brake Thermal Efficiency (BTE)}

Penelitian ini menggunakan sistem EGR dan tanpa EGR dengan variasi campuran butanol 5\%, 10\% dan $10 \%$ pada bahan bakar premium. Hasil pengujian BTE dari campuran bahan bakar akan dibandingkan bahan bakar premium murni untuk menentukan BTE tertinggi dengan dan tanpa sistem EGR. Hasil pengujian BTE ditunjukan pada Gambar 3.

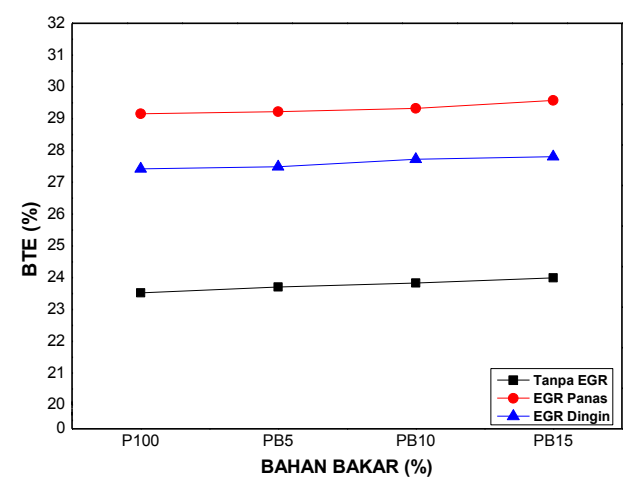

Gambar 3. Brake Thermal Efficiency mesin bensin menggunakan EGR dan tanpa EGR dengan variasi campuran bahan bakar pada

kecepatan putaran mesin $2500 \mathrm{rpm}$.

Hasil pengujian menunjukkan bahwa BTE mengalami peningkatan dengan bertambahnya prosesntase butanol pada bahan bakar premium. Peningkatan BTE tertinggi pada campuran bahan bakar BP15 sebesar $2 \%$ dibanding premium murni (P100). Penambahan butanol pada bahan bakar premium meningkatkan kandungan oksigen. Selain itu, penambahan butanol juga meningkatkan panas laten penguapan campuran bahan bakar sehingga bahan bakar menguap lebih baik di ruang bakar. Hal ini menyebabkan proses pembakaran lebih sempurna sehingga efisiensi termal meningkat [3][4]. Dari hasil studi dapat ditunjukan bahwa penggunaan EGR meningkatkan BTE. Oksigen yang terbawa oleh gas buang tersirkulasikan kembali pada intake manifold sehingga bercampur dengan udara segar yang masuk ke dalam silinder.
Proses ini menyebabkan kandungan oksigen dalam ruang bakar meningkat yang mengakibatkan pembakaran lebih sempurna dan meningkatkan efisiensi termal mesin [8]. Penggunaan EGR panas meningkatkan BTE tertinggi hingga 23,93\% dibanding tanpa EGR.

3. Emisi Gas Buang Carbon Monixide (CO) dan Hidrocarbon (HC)

Pengujian ini dilakukan untuk mengetahui pengaruh variasi penambahan butanol 5\%, 10\% dan 15\% pada bahan bakar premium dengan menggunakan sistem EGR pada mesin bensin. Hasil pengujian emisi gas buang dari variasi campuran bahan bakar dibandingkan dengan bahan bakar premium murni untuk menentukan emisi gas buang terbaik. Hasil pengujian emisi gas buang CO dan HC dipaparkan pada Gambar 4. dan Gambar 5.

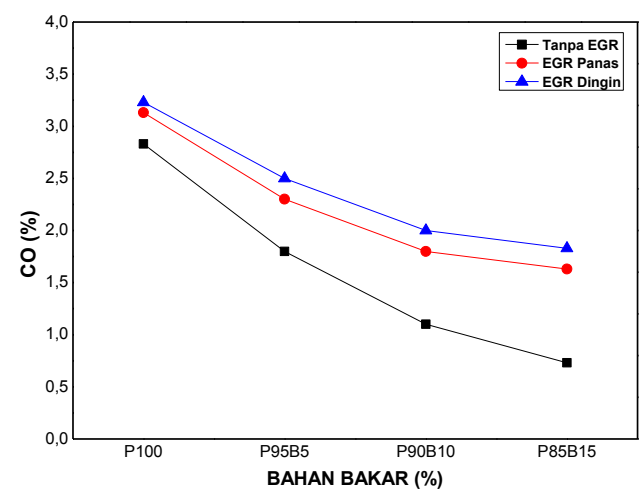

Gambar 4. Emisi gas buang $\mathrm{CO}$ mesin bensin menggunakan EGR dan tanpa EGR dengan variasi campuran bahan bakar pada kecepatan putaran mesin $2500 \mathrm{rpm}$.

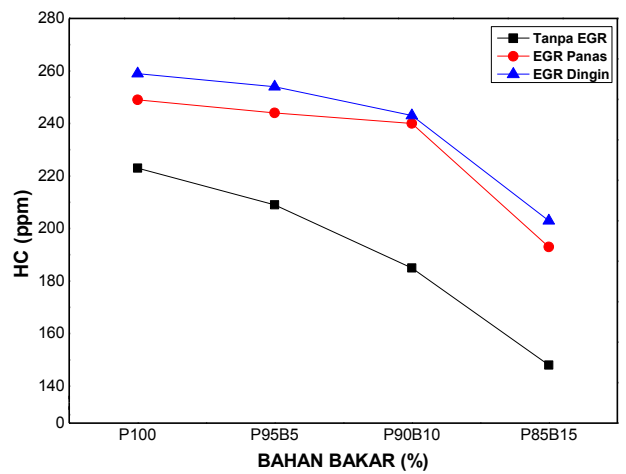

Gambar 5. Emisi gas buang $\mathrm{HC}$ mesin bensin menggunakan EGR dan tanpa EGR dengan variasi campuran bahan bakar pada kecepatan putaran mesin $2500 \mathrm{rpm}$. 
Gambar 4. dan Gambar 5. menunjukkan penurunan emisi $\mathrm{CO}$ dan $\mathrm{HC}$ seiring dengan penambahan prosentase butanol pada bahan bakar premium. Penambahan butanol meningkatkan kadar oksigen pada campuran bahan bakar sehingga effect leaning meningkat. Effect leaning merupakan peningkatan kadar oksigen pada bahan bakar sehingga proses pembakaran lebih sempurna. Proses ini dapat mereduksi emisi CO dan HC [5][15]. Selain itu, butanol juga meningkatkan kecepatan nyala api sehingga pembakaran dalam silinder meningkat yang mengakibatkan penurunan kadar emisi $\mathrm{CO}$ dan HC [2]. Namun, penggunaan EGR meningkatkan emisi CO dan HC. Gas buang yang disirkulasikan kembali oleh EGR menggantikan sebagian udara segar dalam ruang bakar sehingga campuran bahan bakar menjadi heterogen. Campuran bahan bakar yang heterogen memperburuk proses pembakaran sehingga bahan bakar tidak terbakar [16]. Selain itu, penggunaan EGR menurunkan pelepasan panas pada bahan bakar sehingga proses oksidasi memburuk. Proses oksidasi yang buruk menyebabkan proses pembakaran tidak sempurna dan meningkatkan emisi CO dan HC [17][18].

Pada Gambar 4, menunjukkan pengaruh campuran bahan bakar terhadap emisi CO cenderung turun. Penurunan emisi CO tertinggi terjadi pada campuran bahan bakar PB15 sebesar 74,2\% dibanding premium murni. Namun, penggunaan EGR meningkatkan emisi CO. Emisi CO tertinggi 3,23\% terjadi pada penggunaan EGR dingin. Sama halnya emisi CO, pada Gambar 5. menunjukkan penurunan emisi $\mathrm{HC}$ seiring dengan meningkatnya prosesntase butanol pada bahan bakar premium. Penurunan emisi HC tertinggi pada campuran bahan bakar BP15 sebesar 33,6\% dibanding premium murni. Penggunaan EGR dingin meningkatkan emisi HC tertinggi 259 ppm pada penggunaan premium murni.

\section{Kesimpulan}

Brake Spesific Fuel Consumption (BSFC) tertinggi $0,362 \mathrm{~kg} / \mathrm{kW}$.Jam pada campuran bahan bakar PB15. Penurunan BSFC tertinggi $19,33 \%$ pada penggunaan EGR panas dibanding tanpa EGR.

Brake thermal efficiency (BTE) mengalami peningkatan tertinggi $2 \%$ pada campuran bahan bakar PB15 dibanding premium murni. Penggunaan EGR panar meningkatkan BTE tertinggi 23,93\% dibanding tanpa EGR.

Campuran bahan bakar PB15 mereduksi emisi $\mathrm{CO}$ dan $\mathrm{HC}$ tertinggi masing-masing $72,2 \%$ dan $33,6 \%$ dibanding premium murni. Namun, penggunaan EGR meningkatkan emisi $\mathrm{CO}$ dan HC. Emisi CO dan $\mathrm{HC}$ tertinggi masing-masing 3,23\% dan 259 ppm dengan penggunaan EGR dingin.

\section{Referensi}

[1] Syarifudin and Syaiful, 2019, "Pengaruh Penggunaan Energi Terbarukan Butanol Terhadap Penurunan Emisi Jelaga Mesin Diesel Injeksi Langsung Berbahan Bakar Biodiesel Campuran Solar Dan Jatropa," Infotekmesin, vol. 10, no. 1, pp. 18-22.

[2] Yusoff M. N. A. M., et al., 2017, "Performance and emission characteristics of a spark ignition engine fuelled with butanol isomergasoline blends," Transp. Res. Part D Transp. Environ., vol. 57, no. September, pp. 23-38.

[3] Li, Y., et al., 2016, "Effect of watercontaining acetone-butanol-ethanol gasoline blends on combustion, performance, and emissions characteristics of a spark-ignition engine," Energy Conversion and Management, vol. 117. pp. 21-30.

[4] Li, Y., Ning, Z. C. fon F. Lee, Yan, J. and Lee, T. H., 2019, "Effect of acetone-butanol-ethanol (ABE)gasoline blends on regulated and unregulated emissions in sparkignition engine," Energy, vol. 168, pp. 1157-1167.

[5] Zaharin, M. S. M., Abdullah, N. R., Masjuki, H. H., Ali, O. M., Najafi, G., and Yusaf, T., 2018, "Evaluation on 
physicochemical properties of isobutanol additives in ethanol-gasoline blend on performance and emission characteristics of a spark-ignition engine," Applied Thermal Engineering, vol. 144. pp. 960-971.

[6] Ladommatos, N., Balian, R., Horrocks, R., and Cooper, L., 1996, "The effect of exhaust gas recirculation on combustion and $\mathrm{NOx}$ emissions in a high-speed directinjection diesel engine," SAE Tech. Pap., vol. 15, no. 10, pp. 1442-1450.

[7] Xie, F., Hong, W., Su, Y., Zhang, M., and Jiang, B., 2017, "Effect of external hot EGR dilution on combustion, performance and particulate emissions of a GDI engine," Energy Convers. Manag., vol. 142, pp. 69-81.

[8] Wei, H., et al., 2012, "Gasoline engine exhaust gas recirculation - A review," Appl. Energy, vol. 99, no. X, pp. 534-544.

[9] Syarifudin, 2019, "Daya Dan Emisi Jelaga Dari Mesin Diesel Berbahan Bakar Solar-Jatropa-Butanol," $J$. Rekayasa Mesin, vol. 14, no. 3, p. 142.

[10] Chen, Z., Zhang, Y., Wei, X., Zhang, Q., Wu, Z., and Liu, J., 2017, "Thermodynamic process and performance of high nbutanol/gasoline blends fired in a GDI production engine running wideopen throttle (WOT)," Energy Conversion and Management, vol. 152. pp. 57-64.

[11] Agarwal, D., Singh, S. K., and Agarwal, A. K., 2011, "Effect of Exhaust Gas Recirculation (EGR) on performance, emissions, deposits and durability of a constant speed compression ignition engine," Appl. Energy, vol. 88, no. 8, pp. 2900 2907.

[12] C. N. Grimaldi and F. Millo, Internal Combustion Engine (ICE) Fundamentals, vol. 21. 2015.

[13] Feng, H., Zhang, H., Wei, B., Li, and
Wang, D., 2019, "The influence of mixing ratio of low carbon mixed alcohols on knock combustion of spark ignition engines," Fuel, vol. 240, no. 66, pp. 339-348.

[14] Zhang, Z., Zhang, H., Wang, T., and Jia, M., 2014, "Effects of tumble combined with EGR (exhaust gas recirculation) on the combustion and emissions in a spark ignition engine at part loads," Energy, vol. 65, no. x, pp. 18-24.

[15] Sharudin, H., Abdullah, N. R., Najafi, G., Mamat, R., and Masjuki, H. H., 2017, "Investigation of the effects of iso-butanol additives on spark ignition engine fuelled with methanol-gasoline blends," Appl. Therm. Eng., vol. 114, pp. 593-600.

[16] Huang, H., Li, Z., Teng, W., Huang, R., Liu, Q., and Wang, Y., 2019, "Effects of EGR rates on combustion and emission characteristics in a diesel engine with n-butanol/PODE34/diesel blends," Appl. Therm. Eng., vol. 146, pp. 212-222.

[17] Hergueta, C., Bogarra, M., Tsolakis, A., Essa, K., and Herreros, J. M., 2017, "Butanol-gasoline blend and exhaust gas recirculation, impact on GDI engine emissions," Fuel, vol. 208, pp. 662-672.

[18] Ayodhya, A. S., Lamani, V. T., Bedar, P., and Kumar, G. N., 2018, "Effect of exhaust gas recirculation on a CRDI engine fueled with waste plastic oil blend," Fuel, vol. 227, no. X, pp. 394-400. 